\title{
Flame retardant and antimicrobial jute textile using sodium metasilicate nonahydrate
}

\author{
S. Basak", Kartick K. Samanta*, S.K. Chattopadhyay, S. Das, R. Narkar, C. Dsouza, A.H. Shaikh \\ Chemical, Biochemical and Mechanical Processing Division \\ Central Institute for Research on Cotton Technology, Adenwala Road, Matunga, Mumbai-400019, India \\ *Corresponding authors: e-mail: shantanubasak@gmail.com, karticksamanta@gmail.com
}

\begin{abstract}
Flame retardant and antimicrobial functionalities were imparted in jute textile using sodium metasilicate nonahydrate (SMSN), commonly known as "water glass". Sodium metasilicate nonahydrate (SMSN) was applied in jute fabric in different concentration by padding method followed by drying. Flame retardancy of the fabric was evaluated by Limiting Oxygen Index (LOI) and burning behaviour under vertical flammability tester including the char length. Burning rate was found to decrease by almost 10 times after an application of $2 \%$ SMSN compared to the control sample. Thermogravimetry (TG) and differential scanning calorimetry (DSC) analysis of both the control and treated jute fabrics were utilized to understand the mechanism of developed flame retardance in jute fabric. It was observed that the SMSN treated samples showed excellent antimicrobial property against both gram positive and gram negative bacteria. Antimicrobial properties of both the control and treated jute fabrics were also measured quantitatively.
\end{abstract}

Keywords: flame retardant, sodium metasilicate nonahydrate, jute, LOI, antimicrobial.

\section{INTRODUCTION}

Jute is one of the important biodegradable, eco-friendly and renewable natural fibres ${ }^{1}$. Apart from its traditional use as a packaging material, jute fabrics are now also widely used in furnishing, upholstery and home textiles ${ }^{2}$. Although jute is a lingo-cellulosic fibre, cellulose is the major component, hence jute catches flame readily and burns completely in open atmosphere. As a result of this, jute products, such as curtains, upholstered furniture, home textile products, and automobile interior are difficult to extinguish in the presence of the fire and get quickly damaged ${ }^{3}$. Since the users are more aware of safe life style, demand for diversified value added functional jute products treated with flame retardant properties is steadily increasing. In addition to flame retardant property, demand of health and hygienic jute products to avoid unwanted microbial contamination is also increasing. Therefore, effort is going on to develop dual functional (antimicrobial and flame retardant) jute products for home and technical textile application. Different chemical formulations have been reported for flame retardant finishing of jute fabrics for specific end uses ${ }^{4,6}$. It has been found that Phosphorous based flame retardant along with nitrogenous compound work in synergism and is the most effective formulation reported so arr $^{4}$. However, when jute fabric is treated with such chemicals, it adversely affects the mechanical properties of the fabric, as the finish is applied in acidic condition. Also the treatment process is relatively longer and expensive due to the involvement of large quantity of chemicals and high temperature curing ${ }^{5}$. Among the reported technologies, many of them are non-durable to washing ${ }^{6}$. Treatment of wood was with silicate for flame retardancy was reported ${ }^{7}$. Other lingo-cellulosic non-textile materials like lumber, plywood, particle board and wafer board also have been treated by sodium silicate (not SMSN) and their flame retardancy properties were evaluated ${ }^{8,9}$. Antimicrobial activity of silicate has been reported for food products such as chicken meat ${ }^{10}$, reduction of microbial contamination in water ${ }^{11}$ and imparting the antimicrobial property of silicate based bio-ceramics ${ }^{12}$. However, till date no study is available on antimicrobial finishing of textile substrates using silicate compound (SMSN) to the best of our knowledge.

In this study application of SMSN for dual functionalities such as flame retardant and antimicrobial on jute fabrics have been reported. The process would also help to reduce the cost of production, processing time and effluent load as a single chemical could perform both the functionalities. The flame retardant properties of the control and treated fabrics were examined by the vertical flammability tester and LOI value. The mechanism of developed flame retardance was supported by thermo gravimetric analysis (TGA) and differential scanning calorimetry (DSC). Antimicrobial property of the control and treated fabrics was evaluated quantitatively using the most commonly used gram positive and gram negative bacteria.

\section{MATERIAL AND METHODS}

\section{Material}

Plain woven loom state grey jute fabric (with natural golden colour) of $350 \mathrm{~g}$ areal density with $12 \mathrm{EPI}$ (ends/ inch) and13 PPI (picks/inch) having 200 tex warp yarn count and 240 tex weft yarn counts was used in this study. The sodium metasilicate nonahydrate (SMSN), commonly known as "water glass" was supplied by Qualigens Fines Chemicals, Mumbai. The jute fabric was submerged in 21 of water at room temperatures for $3 \mathrm{~h}$ initially, then dried and conditioned at room temperature and humidity for $12 \mathrm{~h}$. The fabrics were then padded with aqueous 2, 4,6 , and $8 \%(\mathrm{~W} / \mathrm{V})$ solution of $\mathrm{SMSN}\left(\mathrm{Na}_{2} \mathrm{SiO}_{3}, 9 \mathrm{H}_{2} \mathrm{O}\right)$ at the room temperature and then dried at $110^{\circ} \mathrm{C}$ for 5 min. During the application of SMSN by pad-dry method wet pick-up was $80 \%$. Before any characterization, the jute fabrics were conditioned in standard atmosphere $\left(27^{\circ} \mathrm{C}\right.$ and $\left.65 \% \mathrm{RH}\right)$ for $48 \mathrm{~h}$. 


\section{Thermal characterization of the fabrics}

\section{(i) Flammability assessment}

Vertical flammability of the control and treated samples was measured by 11871 (A) method, in terms of flame time, after glow time, burning rate and char length. For LOI analysis, ISO1501 test method was used.

\section{(ii) Thermogravimetry (TG)}

Thermogravimetry measures the change in weight loss of a sample with respect to time or temperature. It also provides information about thermal stability of a polymer ${ }^{10}$. The TGA of the control and treated fabrics were carried out in $\mathrm{N}_{2}$ atmosphere using Thermo Gravimetric Analyser (METTLER TOLEDO TG-50/ MT5) over the temperature range of 50 to $800^{\circ} \mathrm{C}$. During the analysis, the rate of heating was kept at $10^{\circ} \mathrm{C} / \mathrm{min}$.

\section{(iii) Differential Scanning Calorimetry (DSC)}

DSC of the control and SMSN treated jute fabrics was carried out using a METTLER TOLEDO DSC-30 thermal analyser. The heating rate was maintained at $10^{\circ} \mathrm{C} / \mathrm{min}$ in a $\mathrm{N}_{2}$ atmosphere.

\section{Physical and chemical characterization}

\section{(i) Determination of add-on $\%$}

In all the treated fabrics, the add-on percentage was determined by a gravimetric method by measuring the bone dry weight of the sample before and after the treatment and expressing the result as a percentage based on the initial bone dry weight of the sample, as per the below formula.

Add-on $\%=\left[\left(\mathrm{M}_{2}-\mathrm{M}_{1}\right) / \mathrm{M}_{1}\right] \cdot 100$

Where: $M_{1}$ and $M_{2}$ are the bone dry weights of the control and treated fabric samples, respectively. The reported results are average of five readings.

\section{(ii) FTIR Analysis}

The control and SMSN treated jute fabrics were analysed using FTIR spectroscopy, Model Shimadzu FTIR spectrometer (IR Prestige-21) to find out different chemical groups. The FTIR spectra were recorded for jute samples by making KBR pellets.

\section{(iii) Antimicrobial assay}

Different concentrations of SMSN solution were screened for antibacterial activity by agar well diffusion method with a cork borer of size $9 \mathrm{~mm}$. For both bacteria overnight broth cultures grown at $37^{\circ} \mathrm{C}$ were used. An aliquot $(0.1 \mathrm{ml})$ of the tenfold diluted inoculum was seeded in to molten and cooled to $45^{\circ} \mathrm{C}$ nutrient agar buffs and overlaid on sterile nutrient agar. The wells were then punched with exactly $0.1 \mathrm{ml}$ of $2,4,6$, and $8 \%$ of the SMSN solution and introduced into the wells allowing $10 \mathrm{~min}$ for diffusion at $4^{\circ} \mathrm{C}$ followed by an incubation period of $24 \mathrm{~h}$ at $37^{\circ} \mathrm{C}$. The antibacterial activity was evaluated by measuring the size of zone of inhibition of bacterial growth around the well.

For quantitative analysis, the percentage reduction in the control and SMSN treated jute fabrics was calculated as per the AATCC-100-2004 standard. In this method, the control and treated swatches were inoculated with the test organism. After incubation, the bacteria were eluted from the swatches by shaking with a known amount of neutralising solution, serially diluted and plating out by standard plate count. The number of bacteria present in this liquid was determined and then expressed as percent reduction as per the below formula.

Reduction in the number of colonies $(\%)=(\mathrm{A}-\mathrm{B}) / \mathrm{A} \cdot 100$

Where: $A$ is the number of bacteria recovered from the inoculated treated test specimen swatches immediately after inoculation (at " 0 " contact time) and B is the number of bacteria recovered from the inoculated treated test specimen swatches incubated over the desired contact period. In both the cases Staphylococcus aureus (Sa) (Gram positive) and Klebsiella pneumoniae (Kp) (Gram negative) bacteria were used.

\section{(iv) Scanning electron microscopy}

Scanning electron microscope images of the untreated and $8 \%$ SMSN treated jute fabrics were taken to analyze the surface coating/deposition of SMSN at a magnification of 1200X using Philips SEM, Model XL-30

\section{(v) Tensile strength}

The tensile strength, one of the most important properties of textile was determined in Instron tensile tester as per the ASTM D5035 standard. The values of the control and treated samples were compared to study the effect of SMSN treatment in the mechanical properties of jute fabrics.

\section{RESULTS AND DISCUSSION}

\section{LOI and vertical flammability}

Jute fabrics were treated with different concentration of SMSN, such as 2, 4, 6 and $8 \%$. The results of the flammability and LOI value of both in the control as well as the treated samples are reported in Table 1.

The limiting oxygen index (LOI), a measure of flammability of a material, is defined as the minimum amount of oxygen required in oxygen/nitrogen mixture to support the burning. Any material having the LOI value of 20 or low is easily ignitable and burn rapidly in open atmosphere. The material having the LOI value of $>21$ ignitable but, burn slowly. When the LOI values are above 26, the material (fabric) may be considered as flame retardant ${ }^{3}$. In this study, LOI values of both the control and SMSN treated jute fabrics have been measured and presented in Table 1 . It can be seen that the LOI value of the control jute fabric is 21 , which could burn easily in open atmosphere. However, in all the SMSN treated jute fabrics, the LOI value were found to increase significantly. The LOI increases linearly with increasing SMSN add-on \%. It increased from 21 in the control sample to 29 (almost 1.5 times) in the $2 \%$ SMSN treated sample. In the $8 \%$ treated sample, the LOI value increased to as high as 43 , which is almost double than that of control fabric. As a result of this, the fabric does not catch flame. The LOI values also support the results of the vertical burning behaviour of the control and treated samples. In vertical flammability of control fabric, the flame spread very fast and burnt the entire sample of $4 \times 25 \mathrm{~cm}^{2}$ within $60 \mathrm{~s}$. In 
Table 1. Flammability properties of the control and SMSN treated jute fabrics

\begin{tabular}{|c|c|c|c|c|c|}
\hline \multirow{2}{*}{$\begin{array}{l}\text { Flammability } \\
\text { parameters }\end{array}$} & \multirow[t]{2}{*}{ Control } & \multicolumn{4}{|c|}{$\begin{array}{c}\text { SMSN Treated } \\
\text { Concentration [\%] }\end{array}$} \\
\hline & & 2 & 4 & 6 & 8 \\
\hline Add -on [\%] & 0 & 1.6 & 3.5 & 4.8 & 7 \\
\hline $\mathrm{LOI}$ & 21 & 29 & 32 & 37 & 43 \\
\hline \multicolumn{6}{|c|}{ Vertical flammability } \\
\hline $\begin{array}{l}\text { Status of fabric in } \\
\text { contact of flame }\end{array}$ & $\begin{array}{c}\text { Completely } \\
\text { burnt (with flame) }\end{array}$ & $\begin{array}{l}\text { Completely burnt } \\
\text { (initially with flame } \\
\text { followed by with } \\
\text { afterglow) }\end{array}$ & $\begin{array}{l}\text { Completely burnt (initially } \\
\text { with flame followed by } \\
\text { with afterglow) }\end{array}$ & $\begin{array}{l}\text { Completely burnt } \\
\text { (with afterglow } \\
\text { only) }\end{array}$ & $\begin{array}{l}\text { Little burning } \\
\text { (with afterglow } \\
\text { only for } 30 \mathrm{~s} \text { ) }\end{array}$ \\
\hline $\begin{array}{c}\text { Burning with flame } \\
\text { time [s] }\end{array}$ & 60 & 10 & 5 & Nil & Nil \\
\hline Afterglow time [s] & $\begin{array}{l}0 \text { (as completely } \\
\text { burnt with flame) }\end{array}$ & 600 & 1800 & 2400 & $30^{\mathrm{a}}$ \\
\hline $\begin{array}{c}\text { Total burning time [s] } \\
\text { (flame time }+ \\
\text { afterglow time) } \\
\end{array}$ & $60+0$ & $10+600$ & $5+1800$ & $0+2400$ & $0+30^{b}$ \\
\hline Char length [mm] & - & - & - & - & 7 \\
\hline $\begin{array}{l}\text { Burning rate } \\
{[\mathrm{mm} / \mathrm{min}]}\end{array}$ & 250 & 25 & 8.3 & 6.2 & $N / A^{a}$ \\
\hline
\end{tabular}

${ }^{\mathrm{a}}$ Sample is self extinguishable after $30 \mathrm{~s}$ of afterglow,

${ }^{\mathrm{b}}$ Total burning time of the fabric $=$ combustion with flame time + combustion with afterglow time (after flame stopped).

the case of only $2 \%$ SMSN treated sample, the fabric showed the reduced flame time of $10 \mathrm{~s}$ followed by its complete burning with afterglow in $600 \mathrm{~s}$. Hence, the total burning time became $610 \mathrm{~s}$. The results indicate that when the sample treated with $2 \%$ SMSN, its total burning time could be increased by approximately 10 folds (control sample $60 \mathrm{~s}$ ). It is important in real life situation, because the user will be getting more escape time $(600 \mathrm{~s})$ to move from hazards zone. In addition, it is also helpful as combustion with afterglow is not so severe in comparison to combustion with flame. Figure 1 represents the vertical burning behaviour of the control and treated samples, $60 \mathrm{~s}$ after removal of flame (flame used to ignite the sample). It was interesting to note that the flame time, which is more severe, could be reduced from $60 \mathrm{~s}$ to 10,5 , and $0 \mathrm{~s}$ in the 2,4 and $6 \%$ SMSN treated samples, respectively. In the treated samples as LOI value increased with percentage application of SMSN, afterglow time was also found to increase linearly to 600,1800 and 2400 s in the 2, 4 and $6 \%$ SMSN treated samples, respectively. This is an indication of that burning rate of the sample is reducing. The burning rate reduced from 250 to $25 \mathrm{~mm} / \mathrm{min}$ in the control to $2 \%$ treated SMSN samples. It further decreased with increasing percentage application of SMSN. The 8\% treated sample does not catch flame, however, the sample burn partially for only $30 \mathrm{~s}$ with afterglow and then self extinguished. As a result of this, $7 \mathrm{~mm}$ char length was observed.

Durability of the imparted finish to soap washing was studied to evaluate its effectiveness in some application, where the sample may undergo limited washing. The $8 \%$ SMSN treated jute fabric was washed as per the method ISO 2. It was observed that after soap washing, LOI value decreased from 43 in the as-prepared sample to 30 in the washed sample. However, the measured LOI value of 30 is still significantly higher than 21 , measured in the untreated sample. After washing, the sample could be compared with $2 \%$ SMSN treated sample. The washed sample in vertical flammability test could sustain flame only for $15 \mathrm{~s}$, thereafter burnt completely with afterglow in $600 \mathrm{~s}$. Hence, the total burning time becomes $615 \mathrm{~s}$, which is significantly more than the untreated sample $(60 \mathrm{~s})$. From the LOI value, flame time and afterglow time, it can be said that sample after washing could retain significant amount of flame retardant property. It might be due to the electrostatic inter-attraction and complex formation of SMSN with hydroxyl groups of the cellulose. As the majority of jute product does not

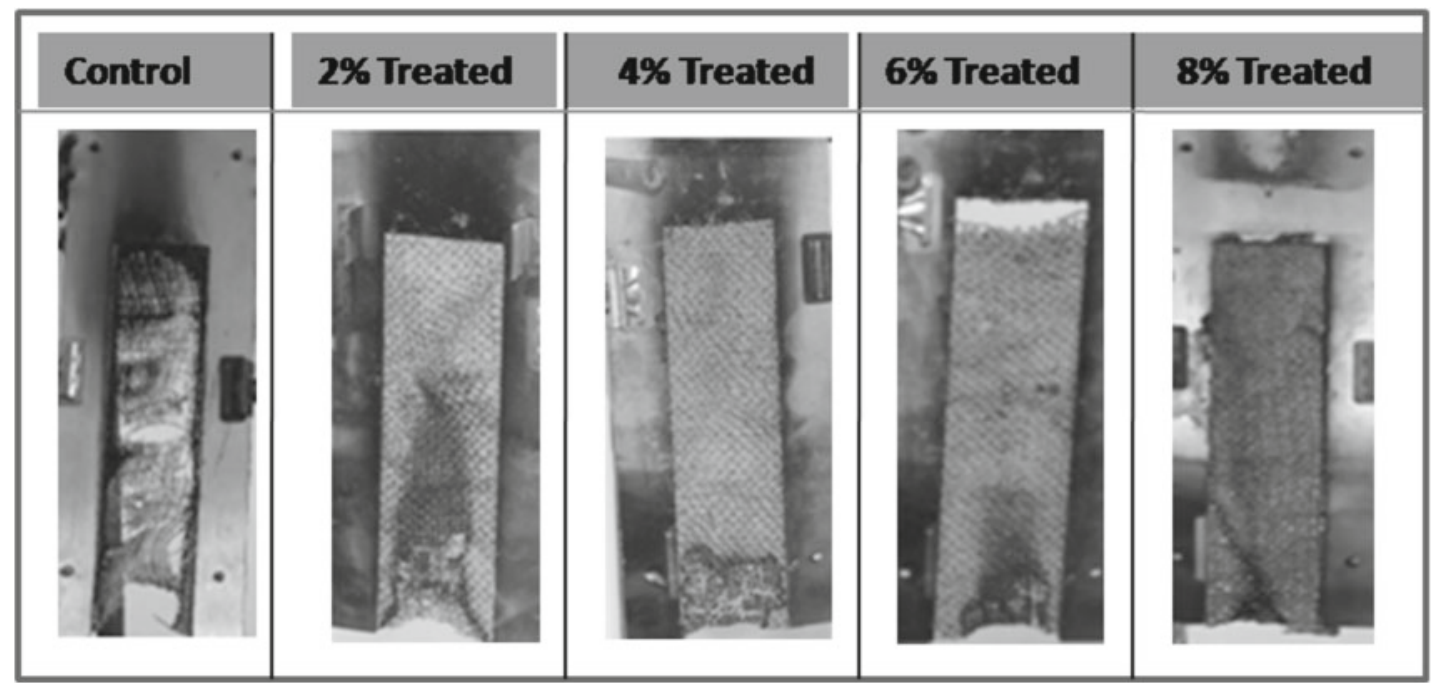

Figure 1. Burning behaviour of the control and SMSN treated samples (60 s after removal of flame) 
undergo washing treatment hence, SMSN treatment could be used to impart semi-durable flame retardant finishing.

\section{Thermogravimetry}

Thermo gravimetric analysis (TGA) was used to measure the application of SMSN on the thermal degradation of the fabrics ${ }^{13}$. Figure 2 shows the TGA curves of the control (A), 4\% SMSN treated jute fabric (B), 8\% SMSN treated jute fabrics $(\mathrm{C})$ and pure SMSN (D). The test was carried out in $\mathrm{N}_{2}$ atmosphere at a heating rate of $10^{\circ} \mathrm{C} /$ min. It can be seen that the Thermo gravimetric (TG) curve of pure SMSN showed several small steps in the temperature range of 50 to $200^{\circ} \mathrm{C}$ with significant loss in mass. These are probably due to the loss of unbound and bound water molecules in different ways ${ }^{14}$. After $200^{\circ} \mathrm{C}$, there was no significant change in weight till $800^{\circ} \mathrm{C}$. This shows the good thermal stability of SMSN over the entire temperatures range. The TG curves of the control jute fabric exhibited three distinct stages. The initial stage is below $150^{\circ} \mathrm{C}$, which is mostly due to physical change and the loss of absorbed moisture from the polymer (cellulose \& hemicelluloses) ${ }^{13}, 15$. However, in the second stage, mainly pyrolysis occurred over the temperature range $265-350^{\circ} \mathrm{C}$. In this stage mass loss is very fast and significant. Most pyrolysis products of cellulose are known to be formed in this stage ${ }^{\mathbf{1 6}}$. As jute is a lingo-cellulosic material and predominantly component is cellulose, hence pyrolysis is likely to occur in this stage. In the third stage, above $350^{\circ} \mathrm{C}$, dehydration and char formation occurred. Compared to control jute fabric (A), SMSN treated jute fabrics (B\&C) loses more mass below $150^{\circ} \mathrm{C}$. It may be attributed to the loss of nine molecules of water of SMSN in addition with lose of water molecules of jute fabric. It is more prominent for curve $\mathrm{C}$ as the sample was treated with $8 \%$ SMSN. In the second stage, both the 4 and $8 \%$ treated jute fabrics started to loss its mass due to pyrolysis at $230^{\circ} \mathrm{C}$, which is quite below $\left(35^{\circ} \mathrm{C}\right)$ than the pyrolysis temperature of the control fabric. From the observation, it can be said that the presence of SMSN in the jute fabric, reduces the pyrolysis temperature of the jute fabric and increases the overall resistance of the fabric to ther- mal degradation. The same might be attributed to the dilution of flammable volatile gases by the generation of non oxidizable molecules such as $\mathrm{CO}_{2}$, and $\mathrm{H}_{2} \mathrm{O}$ at comparatively lower temperature ${ }^{17}$.

It can also be seen from the TG curve that in the third stage, the treated fabric started char formation at a lower temperature and the quantity of char residue was higher than that of the control sample. In the $8 \%$ SMSN treated jute fabric $(\mathrm{C})$, the char formation started at $325^{\circ} \mathrm{C}$, slightly at lower temperature than control sample and residual mass increased from 13 to $32 \%$ at $500^{\circ} \mathrm{C}$.

\section{Differential scanning calorimetry (DSC) analysis}

Differential Scanning Calorimetry (DSC) analysis was carried for both the control and SMSN treated jute fabrics to determine the thermal behaviour of the fabrics as shown in Figure 3. An endothermic peak was observed in the temperature range of $50-130^{\circ} \mathrm{C}$ in both the control and SMSN treated jute fabrics correspond to the heat of evaporation of water molecules absorbed in the fabric ${ }^{18}$. The observed endotherm was found to be steeper in the case of the treated fabrics. This might be attributed to the vaporization of nine molecules of water of SMSN from the treated jute fabric in addition with removal of absorbed moisture from the jute fabric. This is because jute could absorb $13 \%$ moisture of its own weight. For the control jute fabric (A), DSC thermogram showed an endothermic minimum at around $380^{\circ} \mathrm{C}$. This endotherm corresponds to the depolymerisation of cellulose with the formation of flammable gases like levoglucosan ${ }^{18}$. At this temperature, pyrolytic degradation took place with rapid cleavage of the glucosidic bond ${ }^{18}$. On the other hand, the DSC thermogram of the treated jute fabrics $(B \& C)$, the endothermic peak reduced to a small endothermic bend at lower temperature (B) or has disappeared (C). Similar to TG analysis, it also showed that the SMSN treatment could dilute the formation of flammable gases resulting increase in LOI value and decrease in flame time and burning rate.

Another observation from DSC thermogram of the treated jute fabrics is the appearance of an exothermic peak at $310^{\circ} \mathrm{C}(\mathrm{C})$ in the $8 \%$ treated sample and at

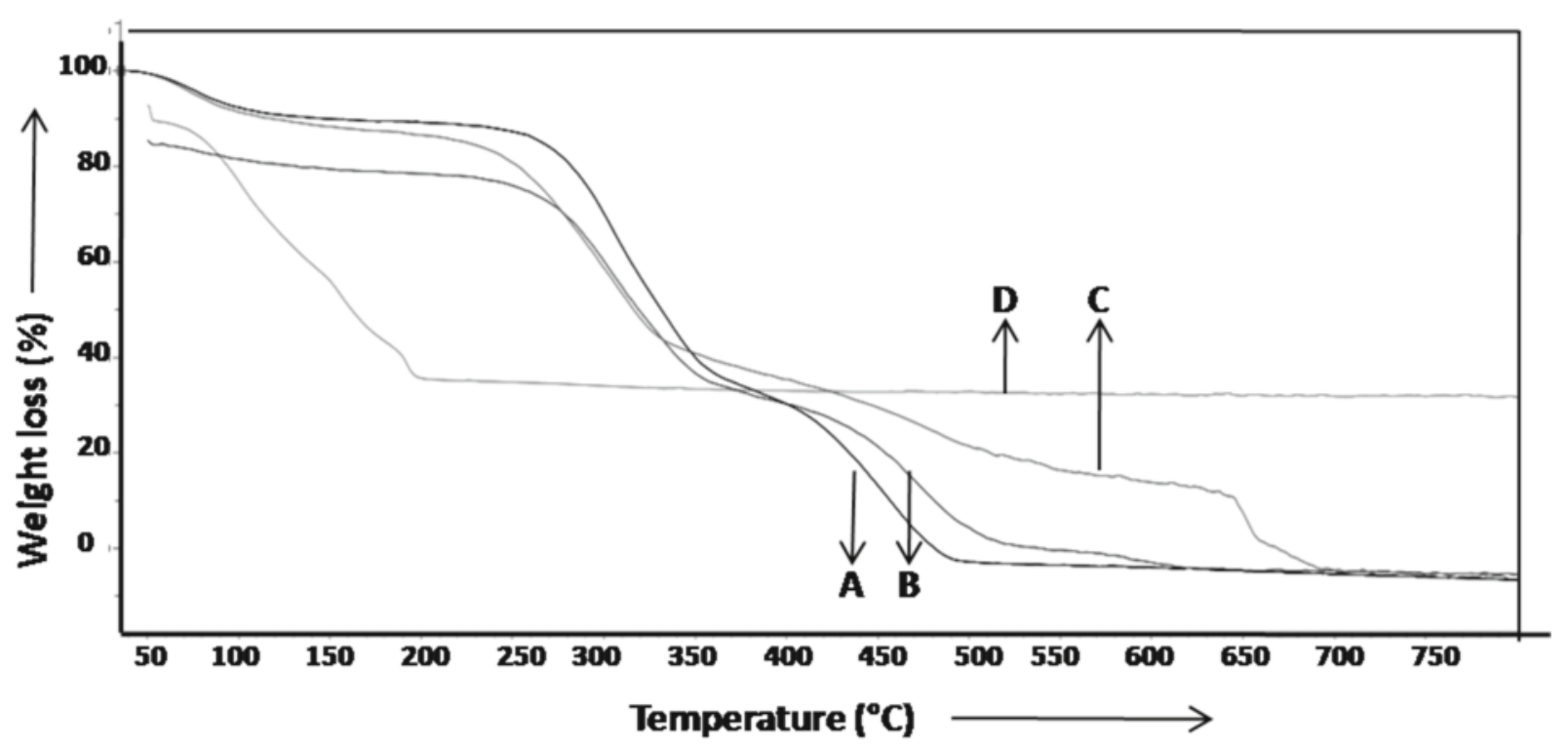

Figure 2. TGA curve of the control jute (A), 4\% SMSN treated jute fabric (B), $8 \%$ SMSN treated jute fabric (C) and pure SMSN (D) 


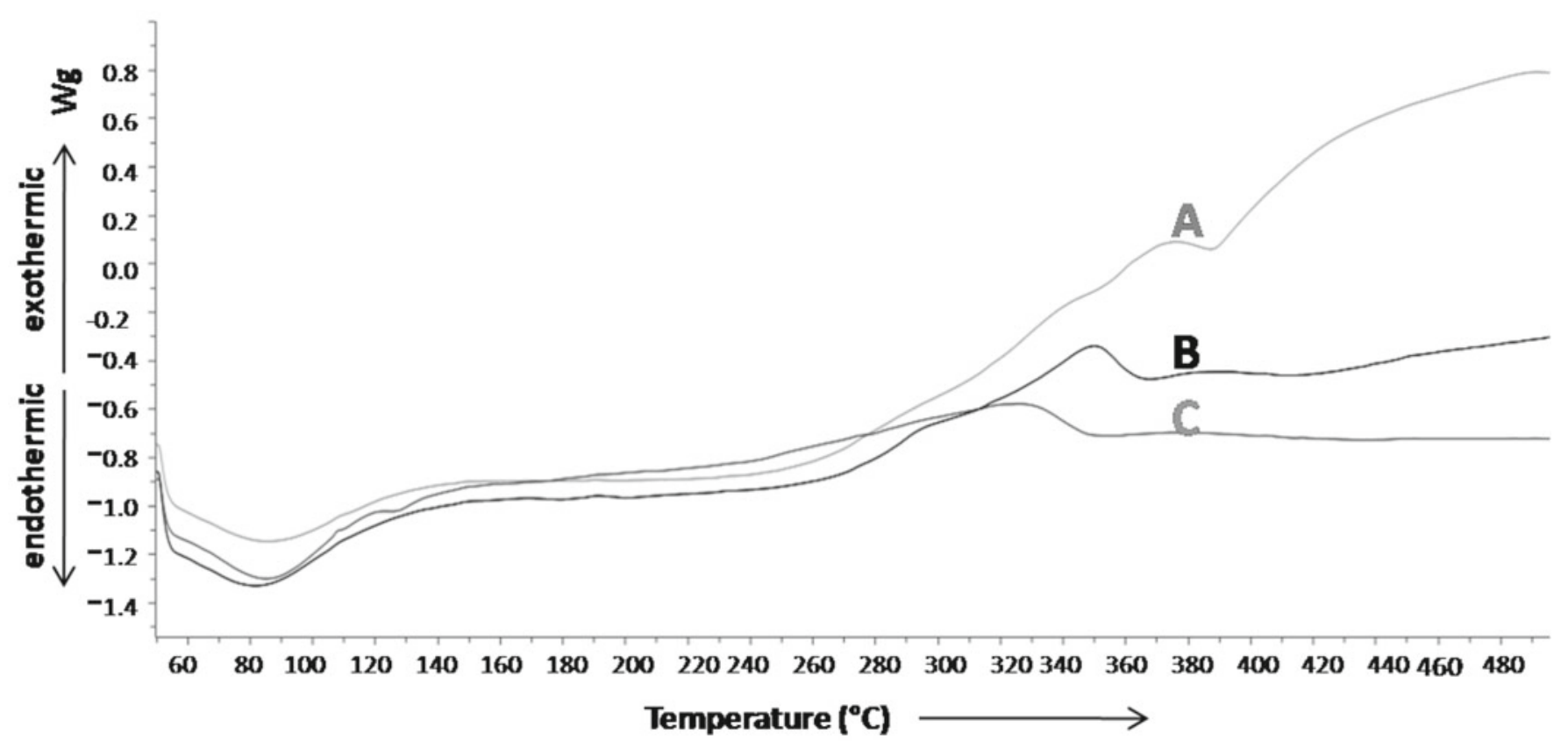

Figure 3. DSC curves of the control (A), $4 \%$ SMSN treated (B) and $8 \%$ SMSN treated (C) jute fabrics

$340^{\circ} \mathrm{C}(\mathrm{B})$ for $4 \%$ treated sample. This exothermic peak is responsible for dehydration of cellulose polymer and char formation ${ }^{15,19}$. Similar phenomenon happened at slightly higher temperature in the control sample (A). It also revealed that the exothermic peak related to dehydration of hemicellulose and cellulose, has shifted to lower temperature in the range of 340 to $310^{\circ} \mathrm{C}$, when the SMSN add-on increased from 4 to $8 \%$. This indicates the presence of SMSN helps in lowering the degradation temperature of the treated jute fabrics and production of more non-flammable gases along with char. Besides the fact, area under the exothermic peak was also found to increase with the increase SMSN content. Therefore, like TG analysis this phenomenon is attributed to the dehydration of cellulose that occurred more extensively as the SMSN content in the fabric was increased.

\section{Antimicrobial assay}

Antimicrobial assay of SMSN solution is presented in Figure 4. It is evidenced that SMSN solution had inhibited both the gram positive and the gram negative bacteria. It can be observed from the Table 2 that antibacterial activity was increased gradually with increasing percentage application of SMSN. Thus at $8 \%$ concentration, the diameter of the zone of inhibition was found $18 \mathrm{~mm}$ and $17 \mathrm{~mm}$ against Staphylococcus aureus (Sa) and Klebsiella pneumonia (Kp) bacteria, respectively.

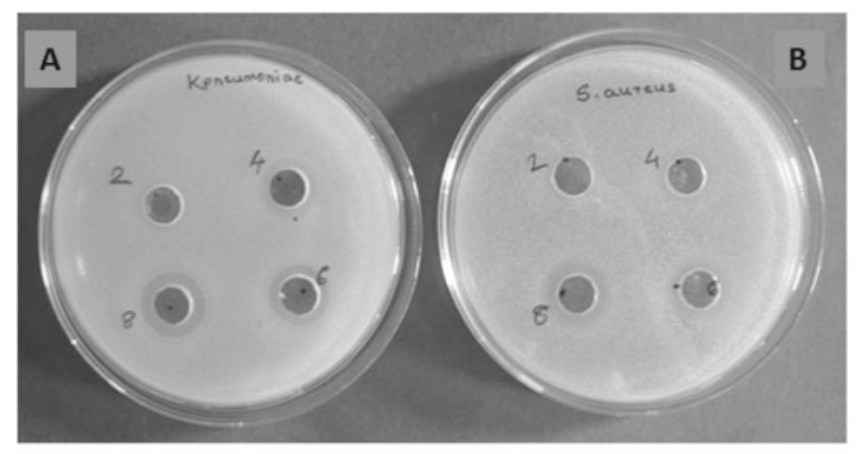

Figure 4. Zones of inhibitions produced by SMSN solutions against $\mathrm{Kp}(\mathrm{A})$ and $\mathrm{Sa}(\mathrm{B})$
Quantitative evaluation of anti-bacterial activity was carried out on both the control and SMSN treated jute fabrics against $S$. aureus and $K$. pneumoniae as per the AATCC-100-2004 standard. A typical photograph of bacterial reduction is shown in Figure 5. The quantitative information of the antimicrobial activity has also presented in Table 2. It can be seen that the $2 \%$ SMSN treated fabric has $62.2 \%$ potential to reduce the colony growth against $\mathrm{Sa}$ bacteria. The reduction in bacterial growth was increased up to $99.9 \%$ in the $8 \%$ treated jute fabric, which is consider to be an excellent antibacterial textile material. Similar trend in antibacterial functionality was also observed when the SMSN treated fabric was evaluated against Kp bacteria. From the result, it is seen that SMSN treatment is more effective against

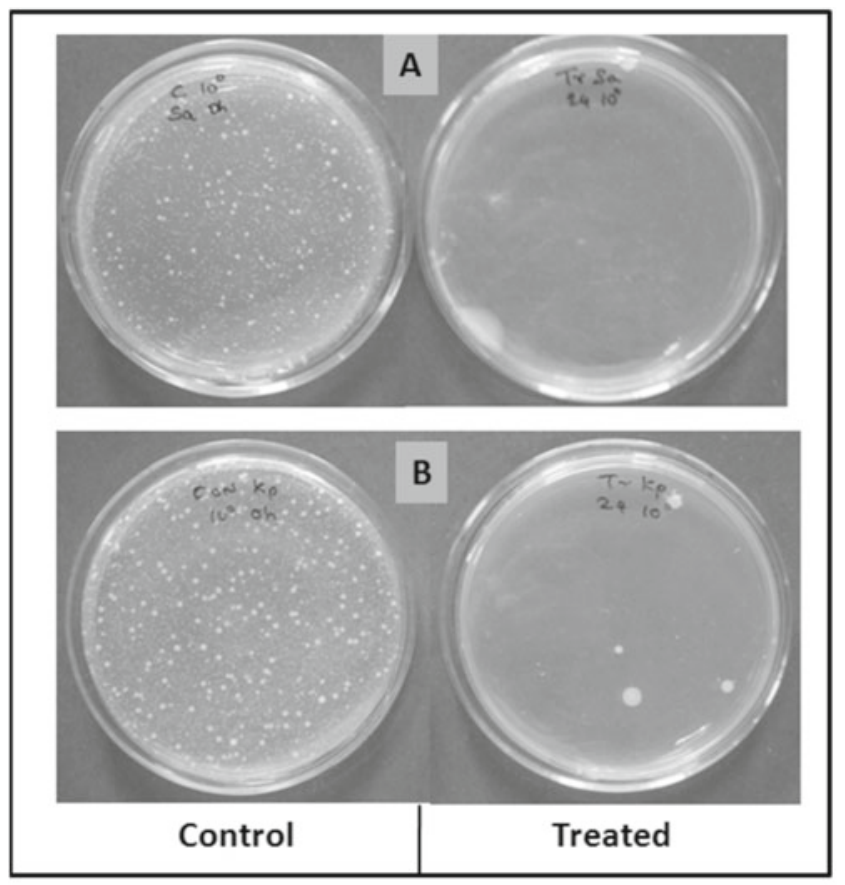

Figure 5. Bacterial reduction in the $8 \%$ SMSN treated jute fabrics against (A) Staphylococcus aureus $(\mathrm{Sa})$ and (B) Klebsiella pneumonia $(\mathrm{Kp})$ bacteria compared to control sample 
Table 2. Qualitative and quantitative antimicrobial data SMSN solution and treated jute fabrics

\begin{tabular}{|c|c|c|c|c|c|}
\hline \multirow{3}{*}{$\begin{array}{l}\text { Concentration of SMSN } \\
\text { solution }[\%][\mathrm{W} / \mathrm{V}]\end{array}$} & \multirow{2}{*}{\multicolumn{2}{|c|}{$\begin{array}{c}\text { Qualitative data } \\
\text { diameter of zone of inhibition [mm] }\end{array}$}} & \multirow{3}{*}{$\begin{array}{c}\text { Application of SMSN } \\
\text { solution [\%] on the jute } \\
\text { fabrics }\end{array}$} & \multicolumn{2}{|c|}{ Quantitative data } \\
\hline & & & & \multicolumn{2}{|c|}{ bacterial reduction $\%$ in the treated fabric } \\
\hline & $\mathrm{Sa}$ & $\mathrm{Kp}$ & & $\mathrm{Sa}$ & $\mathrm{Kp}$ \\
\hline Control & 0 & 0 & Control & 0 & 0 \\
\hline 4 & 12 & 11 & 4 & 84.3 & 94.3 \\
\hline 6 & 16 & 15 & 6 & 95.4 & 99.9 \\
\hline 8 & 18 & 17 & 8 & 99.9 & 99.9 \\
\hline
\end{tabular}

Note: Sa - Staphylococcus aureus (gram positive) and Kp - Klebsiella pneumonia (gram negative).

gram negative $(\mathrm{Kp})$ bacteria compared to gram positive (Sa) bacteria. The antibacterial activity in the treated fabrics might be attributed to high $\mathrm{pH}$ of $\mathrm{SMSN}^{20}$ and breakage of membrane integrity of bacteria and disruption of cytoplasmic membrane. Similar phenomenon has also been reported in the literature ${ }^{10-12}$.

\section{FTIR analysis of fabrics}

The FTIR analysis was carried out for both the control (A) and SMSN treated jute fabrics $(\mathrm{B} \& \mathrm{C})$ as shown in Fig. 6. The strong intense IR band was observed at $4000 \mathrm{~cm}^{-1}$ in the 4 and $8 \%$ treated samples (B\&C). Compared to the control jute fabric (A), this band is more intense in treated fabrics $(\mathrm{B} \& \mathrm{C})$. It might be due to the stretching vibration of water molecules present in SMSN and jute fabric. In case of $8 \%$ SMSN treated fabric (B), the small shoulder observed at $3625 \mathrm{~cm}^{-1}$ might be due to stretching vibrations of $\mathrm{Si}-\mathrm{OH}$ groups ${ }^{21}$. Strong IR band at $1060 \mathrm{~cm}^{-1}$ is assigned to the $\mathrm{Si}-\mathrm{O}$ stretching vibration $^{21-22}$. The presence of these peaks ensures the presence of SMSN in the jute fabrics and also helped to impart antimicrobial functionality.

The band near to $1750 \mathrm{~cm}^{-1}$ was assigned to the C-O stretching of the $\mathrm{COOH}$ and acetyl groups of hemicellulose of jute fabric ${ }^{23}$. It was prominent in control jute fabric but shifted to $1700 \mathrm{~cm}^{-1}$ and intensity decreases with increasing the concentration of SMSN on the fabric. This might be attributed with the more $\mathrm{pH}$ value of the SMSN in solution, which might have affected partially, the amorphous hemicellulose part of the jute fabric.

\section{Scanning electron microscopy}

Figure 7 shows the SEM micrograph of the untreated and $8 \%$ SMSN treated jute fabrics at a magnification of 1200X. It can be seen from Figure 7a that it has clean surface and individual fibrils are also visible. On the other hand, in the SMSN treated sample fine coating is visible and also surface became rougher (Fig. 7b). This may be due to coating of SMSN on the jute fabric.

\section{Mechanism of flame retardant property}

The application of SMSN possibly forms a silicate coating on the surface of the jute fabric, which act as an intumescent as reported in the literature for non-textile substrates ${ }^{7}$. It also acts as a hydrated plaster. Upon exposure to high temperature, it swells and increases in volume and decrease density. It also forms an insulating carbonaceous foamy glassy layer on the surface of the fabric $^{7,13,24}$. This insulating layer contains char producing compound such as polyol, which normally burns to produce non-oxidizable gases like $\mathrm{CO}, \mathrm{H}_{2} \mathrm{O}$ and $\mathrm{CO}_{2}$. These generated gases might have also diluted the flammable gases such as levoglucosan and pyroglucosan produced during pyrolysis of jute in the burning microclimate ${ }^{7,17}$. In addition the chemically bound nine molecules of water with SMSN absorb significant amount of heat during burning and helped in lowering down the fire propagation.

The presence of SMSN had an effect on lowering dehydration temperature of cellulose and higher char formation as observed from TGA analysis. Better thermal

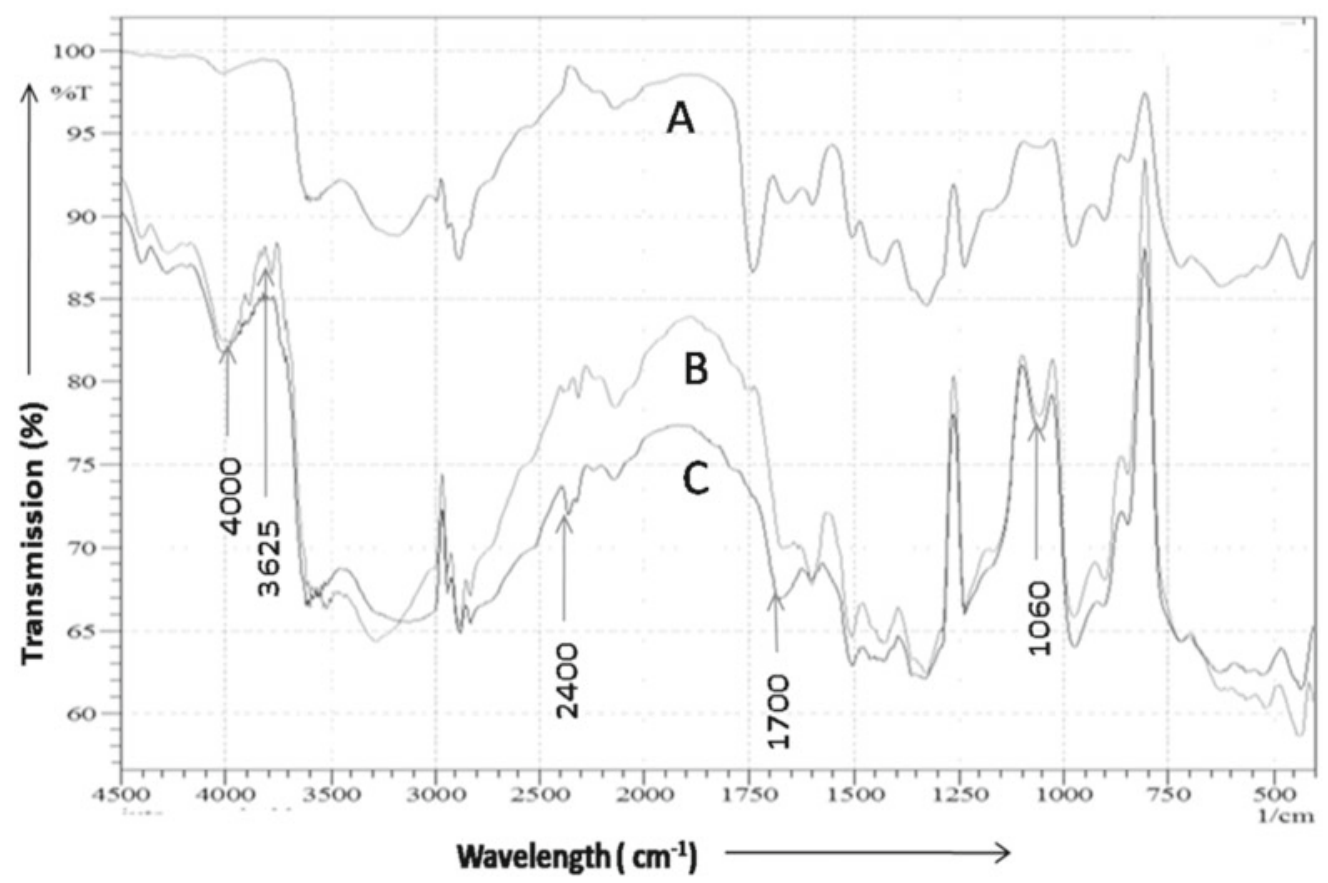

Figure 6. FTIR spectra of the control (A), $8 \%$ SMSN treated (B) and $4 \%$ SMSN treated (C) jute fabrics 


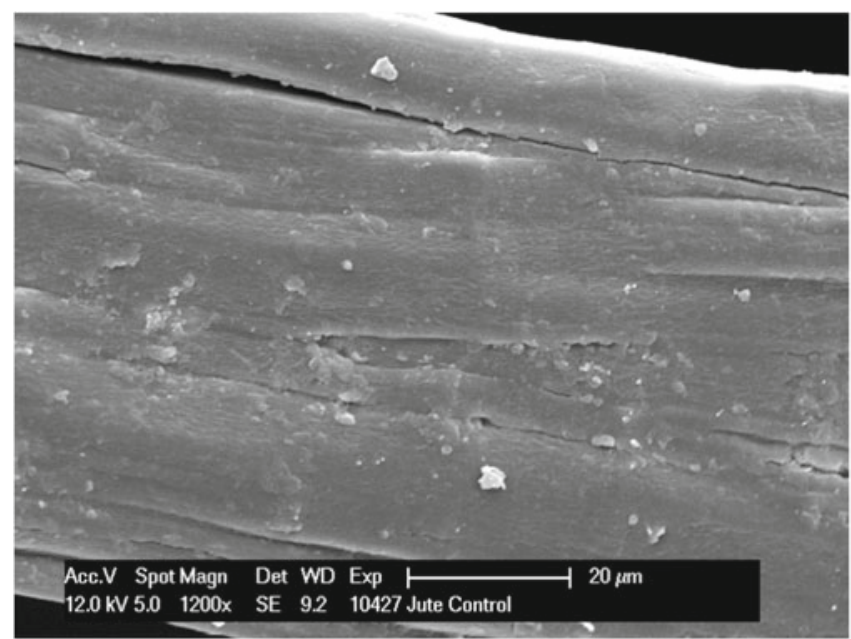

(a)

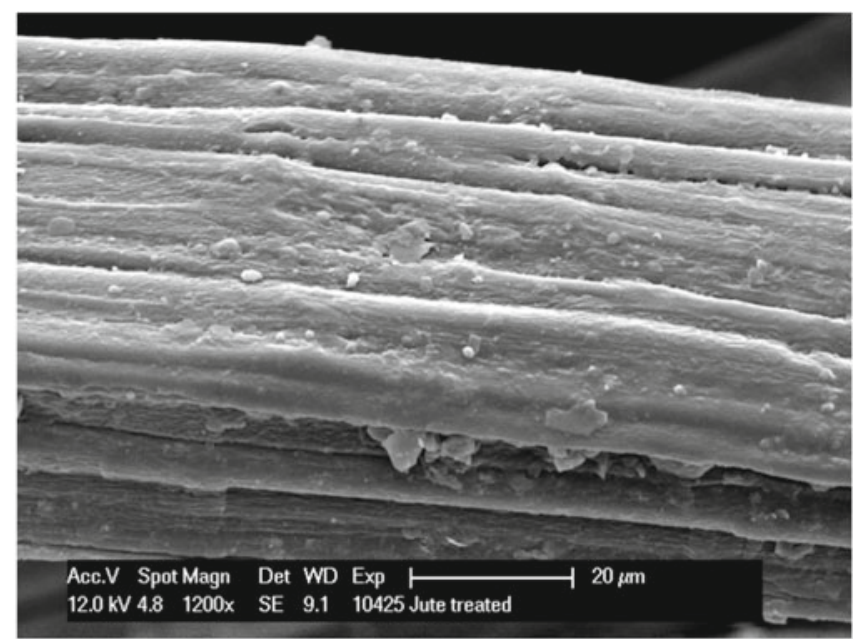

(b)

Figure 7. SEM micrograph of the control (a) and $8 \%$ SMSN treated (b) jute fabrics

stability of the SMSN treated sample over the temperature range of 50 to $800^{\circ} \mathrm{C}$ has also been observed. The DSC analysis showed that the presence of SMSN could help in lowering the degradation temperature of jute from 340 to $310^{\circ} \mathrm{C}$ in addition with the production of more non-flammable gases and char. The increase in exothermic peak with the increasing SMSN content is attributed to extensively dehydration of cellulose. Therefore, in the SMSN treated samples, the reduction in flammable gas formation, increase in char formation, formation of glassy insulating layer on the surface and consumption of more heat energy for removal of water molecules (of SMSN and fabric) might have helped in overall thermal resistance of treated fabric compared control fabric.

\section{Mechanical strength}

Unlike the chemical processing of cellulose (cotton) textile in alkaline condition, small loss in tensile strength generally occurs for lingo-cellulosic textile (jute) due to partial removal of lignin and hemi-cellulose. On the other hand, chemical processing of cellulosic and lingo-cellulosic textile in acidic condition significantly reduces the tensile strength due to cleavage of glucocydic linkage of cellulose polymer. Many of the existing formulation of flame retardant finish reduce the tensile strength up to $30 \%$ as they are applied in acidic conditions. Unlike the existing process, in our experiment as flame retardant finishing was applied in alkaline condition, there was no significant adverse effect in tensile strength. In the $2 \%$ SMSN treated samples there was only 3.7 and $7.5 \%$ reduction of tensile strength in wrap and weft direction, respectively. In the case of $8 \%$ SMSN treated samples there was 6 and $15 \%$ loss in tensile strength in warp and weft direction of the fabric, respectively. This change in tensile property may be due to mild adverse effect of alkali (of SMSN) on lignin and hemicelluloses of the jute fabric ${ }^{23}$.

\section{CONCLUSION}

The present study showed both the flame retardancy and antimicrobial properties of SMSN on jute fabrics. As far as flammability and antimicrobial properties are concerned, the $8 \%$ formulation was found to be superior for the application on jute fabric by the padding method. Thermogravimetry and differential scanning calorimetry analysis showed flame retardant action in the SMSN treated samples due to formation of glassy insulate layer on the surface and dehydration of cellulose by losing non-flammable gases like $\mathrm{CO}_{2}, \mathrm{H}_{2} \mathrm{O}$ etc at lower temperature. The LOI value was found to increase from 21 in the control sample to 43 in the $8 \%$ SMSN treated sample. As a result of this, it does not catch flame and afterglow was also self extinguishable within $30 \mathrm{~s}$ only. The combustion time of a $25 \mathrm{~cm} \times 4 \mathrm{~cm}$ increased from only $60 \mathrm{~s}$ in the control to $2400 \mathrm{~s}$ in the $6 \%$ treated samples. This could provide much longer escape time in the case of fire situation to its user or valuable products, where jute would be used as a packaging material. The application process is simple and cost effective as no high temperature process is involved. Both the SMSN solution and the treated fabrics showed resistance to gram positive and gram negative bacteria. There was no microbial growth in the $8 \%$ SMSN treated jute fabrics. The SMSN is odourless and non-toxic, hence the developed process is environmental friendly. If the fabric is meant for application as interior material for passenger cars, trucks, buses and for making decorative home furnishing materials like table lamp, wall mat, curtains then this technology would be useful for imparting both the fire retardancy and antimicrobial properties. Since SMSN is abundantly available and inexpensive, developed process technology would be useful to impart dual functionalities i.e. flame retardant and antimicrobial in jute textile.

\section{LITERATURE CITED}

1. Dutt, R. (2008, April). Ecofriendly biodegradable handicrafted jute products for the leisure \& hospitality sector. Retrieved May 30, 2009, from http://www.pressreleasepoint.com/eco-friendly

2. Chattopadhyay, S.N., Pan, N.C., Day, A. \& Roy A.K. (2011, December). Coloration of jute fabric by single bath bleaching-dyeing process. Fibre 2 fashion. Retrieved December 16, 2012, from http://www.fibre2fashion.com

3. Charuchinda, S., Srikulkit, K. \& Mowattana, T. (2005). Co-application of sodium polyphosphateand chitosan to improve flame retardancy of cotton fabric. J. Sci. Res.Chula.Univ., 30 (1), 97-110. DOI: 10.1177/0734904112443658.

4. Kandola, B.K., Horrocks, A.R., Price, D. \& Coleman G.V. (2006). Flame retardant treatments of cellulose and their influ- 
ence on the mechanism of cellulose pyrolysis. J. Macromol.Sci., 36(4), 721-794. DOI: 10.1080/15321799608014859.

5. Sharma, U. (1986). Fire retardancy of jute fabrics with PST (Rochelle salt). Colourage, 32(26), 19-20. ISSN: 0010-1826.

6. Schindler, D.W. \& Hauser P.J. (2004). Chemical finishing of textiles, USA: Woodhead publishers.

7. Rowell, R.M. \& Dietenberger, M.A. (2013). Handbook of Wood Chem. and Wood Composites. In R.M. Rowell (Eds.), Thermal properties, combustion and fire retardancy of wood (pp. 127-149). Taylor \& Francis Group: London Newwork CRC press.

8. Helmstetter, J.G. (1995). U.S. Patent No.5453119A. Washington, DC: U.S. Patent and Trademark Office.

9. Slimak, K.M., \& Slimak, R.A. (2001). U.S. Patent No. US6303234B1. Washington, DC: U.S. Patent and Trademark Office.

10. Huang, H., Williams, S.K., Sims, C.A. \& Simmone A. (2011). Sodium metasilicate affects antimicrobial, sensory, physical, and chemical characteristics of fresh commercial chicken breast meat stored at $4^{\circ} \mathrm{C}$ for 9 days. Poul. Sci., 90 (5), 1124-1133. Doi: 10.3382/ps.2010-01227.

11. Vatten, D.A., Maitin, V. \& Richardsons, C.R. (2012). Evaluation of antibacterial and toxicological effects of a novel sodium silicate complex. Res. J. Microbiol., 7 (3), 191-198. DOI: 10.3923/jm.2012.191.198.

12. Sheng, H.U., Congqin, N., Yue, Z., Chen, L., Kaili, L. \& Jiang, C. (2011). Antibacterial activity of silicate bioceramics. J. Wuhan Univ. Technol., 26 (2), 226-230. DOI: 10.1007/ S11595-011-0202-8.

13. Karastergiou, P.S. \& Philippou, J.L. (2000). Wood and Fire Safety. In J.L.Philippou (Eds.), Thermogravimetric analysis of fire retardant treated particle boards (pp. 385-394). Thessaloniki: Greece

14. Kyeong, W.P. (2012). Ion Exchange Technologies. In A. Kilislioglu (Eds.), Ion exchange and application of layered silicate (pp. 241-259). Intech Publishers. DOI: 10.57772/ 51564.

15. Xing, T.L., Liu., J., Li, S.W. \& Chen, G.Q. (2012). Thermal properties of flame retardant cotton fabric grafted by dimethyl methacryloyloxyethyl phosphate. Thermal Sci., 16 (5), 1472-1475. DOI: 10.2298/TSCI1205472X

16. Mostashari, S.M. \& Mostashari, S.Z. (2009). Thermogravimetry of deposited ammonium aluminium sulphate Dodecahydrate used as flame retardant for cotton fabrics. Cellul. Chem. and Technol., 43 (9-10), 455-460.

17. Loelovich, M. \& Figovsky, O. (2003). Advanced environmental friendly polymer materials. Polym. Adv. Technol. 13(10-12), 112-1115. DOI: 10.1002/pat.282.

18. Pandey, S.N., Day, A. \& Mathew M.D. (1993). Thermal analysis of chemically treated jute fibres. Textile Res. J., 63 (3), 143. DOI: $10.1177 / 004051759306300303$.

19. Jain, R.K., Lal, K. \& Bhatnagar, H.L. (1985). Thermal degradation of cellulose and its phosphorylated products in air and nitrogen. J. Appl. Poly. Sci., 30 (3), 897-914. DOI: 10.1002/ app.1985.070300302.

19. Sharma, C.S., Williams, S.K., Schenider, K.R. \& Schmidt, R.H. (2012). Antimicrobial effects of sodium metasilicate against Listeria monocytogens. Food. Pathog. Disease, 9 (9), 822-828, DOI: $10.1089 / \mathrm{fpd} .2012 .1207$.

20. Music, S., Vincekovic, F.N. \& Sekovanic L. (2011). Precipitation of amorphous $\mathrm{SiO}_{2}$ particles and their properties. Brazilian J. of Chem. Engine., 28(1), 89-94. DOI: 10.1590/ S0104-66322011000100011.

21. De-guang, C.A.O. \& Da-gen, S.U. (2005). Structure characterization of geopolymer of sodium silicate and metakaolin. Mat. Sci. Appl. Chem., 4 (2), 70-73. DOI: 1671-8224(2005)020070-04.

22. Sinha, E. \& Rout, S.K. (2009). Influence of fibre surface treatment on structural, thermal and mechanical properties of jute fibre and composites. Bull. Mat. Sci., 32 (1), 65-76. DOI: 10.1007/s12034-008-0143-9.
23. Kashiwagi, T., Gilman, J.W., Butler, K.M., Harris, R.H., Shields, J.R. \& Asano, A. (2000). Flame retardant mechanism of silica gel/ silica. Fire Mat., 24 (6) 277-289. DOI: 10.1002/1099-1018(200011/12)24:6<277::AID-FAM746>3.0.CO;2-A. 